Article

\title{
Determination of the $\mu$-Conotoxin PIIIA Specificity Against Voltage-Gated Sodium Channels from Binding Energy Calculations
}

\author{
Fangling Chen ${ }^{1,2}$, Wenxin Huang ${ }^{1,2}$, Tao Jiang ${ }^{1,2}$ and Rilei Yu ${ }^{1,2, *}$ \\ 1 Key Laboratory of Marine Drugs, Chinese Ministry of Education, School of Medicine and Pharmacy, \\ Ocean University of China, Qingdao 266003, China; Chenfangling0410@hotmail.com (F.C.); \\ annie95116@gmail.com (W.H.); jiangtao@ouc.edu.cn (T.J.) \\ 2 Laboratory for Marine Drugs and Bioproducts, Qingdao National Laboratory for Marine Science and \\ Technology, Qingdao 266003, China \\ * Correspondence: ryu@ouc.edu.cn; Tel.: +86-138-6986-2306
}

Received: 30 March 2018; Accepted: 28 April 2018; Published: 7 May 2018

\begin{abstract}
Voltage-gated sodium $\left(\mathrm{Na}_{\mathrm{V}}\right)$ channels generate and propagate action potentials in excitable cells, and several $\mathrm{Na}_{\mathrm{V}}$ subtypes have become important targets for pain management. The $\mu$-conotoxins inhibit subtypes of the $\mathrm{Na}_{\mathrm{V}}$ with varied specificity but often lack of specificity to interested subtypes. Engineering the selectivity of the $\mu$-conotoxins presents considerable complexity and challenge, as it involves the optimization of their binding affinities to multiple highly conserved $\mathrm{Na}_{\mathrm{V}}$ subtypes. In this study, a model of $\mathrm{Na}_{\mathrm{V}} 1.4$ bound with $\mu$-conotoxin PIIIA complex was constructed using homology modeling, docking, molecular dynamic simulations and binding energy calculations. The accuracy of this model was confirmed based on the experimental mutagenesis data. The complex models of PIIIA bound with varied subtypes of $\mathrm{Na}_{\mathrm{V}} 1 . x(\mathrm{x}=1,2,3,5,6,7,8$, or 9) were built using $\mathrm{Na}_{\mathrm{V}} 1.4$ /PIIIA complex as a template, and refined using molecular dynamic simulations. The binding affinities of PIIIA to varied subtypes of $\mathrm{Na}_{\mathrm{V}} 1 . x(\mathrm{x}=1$ to 9) were calculated using the Molecular Mechanics Generalized Born/Surface Area (MMGB/SA) and umbrella sampling, and were compared with the experimental values. The binding affinities calculated using MMGB/SA and umbrella sampling are correlated with the experimental values, with the former and the latter giving correlation coefficient of $0.41\left(R^{2}\right)$ and $0.68\left(R^{2}\right)$, respectively. Binding energy decomposition suggests that conserved and nonconserved residues among varied $\mathrm{Na}_{\mathrm{V}}$ subtypes have a synergistic effect on the selectivity of PIIIA.
\end{abstract}

Keywords: homology modeling; molecular docking; sodium channel; $\mu$-conotoxin; MD simulation; binding affinity; MMGB/SA; umbrella sampling

\section{Introduction}

The $\mu$-conotoxins are short snail peptide toxins specifically targeting subtypes of $\mathrm{Na}_{\mathrm{V}}$ and are considered as important drug leads. The first step for engineering the specificity of $\mu$-conotoxins is understanding of the molecular interaction mechanism between the $\mu$-conotoxins and varied subtypes of the $\mathrm{Na}_{\mathrm{V}}$. Accurate determination of the molecular determinants that confer the specificity of the $\mu$-conotoxin PIIIA to different $\mathrm{Na}_{\mathrm{V}}$ subtypes is essential for further engineering the specificity of the $\mu$-conotoxins for therapeutic purposes.

\subsection{Function of $\mathrm{Na} a_{V}$}

Voltage-gated sodium $\left(\mathrm{Na}_{\mathrm{V}}\right)$ channels play important roles in cell excitability and mediation of the ionic conductance through the cells [1-3]. Members of the $\mathrm{Na}_{\mathrm{V}}$ channel family are classified 
as $\mathrm{Na}_{\mathrm{V}} 1.1-1.9$ according to the $\alpha$ subunit sequences [4]. Different $\mathrm{Na}_{\mathrm{V}}$ subtypes usually distribute in different areas and have distinctive functions. $\mathrm{Na}_{\mathrm{V}} 1.1,1.2,1.3$ and 1.6 mainly exist in the central and peripheral nervous systems, while the $\mathrm{Na}_{V} 1.7,1.8$ and 1.9 are wildly distributed in peripheral sensory neurons [5,6]. The $\mathrm{Na}_{V} 1.4$ is mainly existing in skeletal muscle [5,6], and $\mathrm{Na}_{\mathrm{V}} 1.5$ is essentially distributed in the cardiac muscle [5,6]. The $\mathrm{Na}_{V} 1.7,1.8$ and 1.9 are associated with neuropathic pain, and are considered as promising analgesic targets with a minimal side effect profile $[5,6]$.

\subsection{Structure of the $\mathrm{Na} a_{V}$}

The eukaryotic $\mathrm{Na}_{\mathrm{V}}$ channels comprise a pore-forming $\alpha$ subunit and one or two $\beta$ subunits (Figure 1A). The $\alpha$-subunit controls sodium ion selection, voltage sensing and inactivation, while the $\beta$ subunit that includes an N-terminal extracellular immunoglobulin-like fold, a transmembrane segment, and intracellular fragments that help regulate channel dynamics, such as activation and inactivation of voltage dependence. The $\alpha$ subunit is a single chain with about $260 \mathrm{kDa}$ in size, and it folds into four homologous repeats (domains I to IV), each containing six transmembrane segments, S1 to S6 (Figure 1). The central pore of $\mathrm{Na}_{\mathrm{V}}$ is enclosed by S5 and $\mathrm{S} 6$ segments, and the selectivity filter (SF) of the pore is constituted of the intervening sequences of S5 and S6 (Figure 1B,C). The cryogenic electron microscopy (cryo-EM) structure of a putative $\mathrm{Na}_{\mathrm{V}}$ channel from American cockroach (designated $\mathrm{Na}_{\mathrm{V}} \mathrm{PaS}$ ) at 3.8 angstrom resolution [7] (Figure 1B) as well as the cryo-electron microscopy (cryo-EM) structure of $\mathrm{Ee} \mathrm{Na}_{\mathrm{V}} 1.4$ from the electric eel [8] give more detailed description of the structure composition of the $\mathrm{Na}_{\mathrm{V}}$ channels.

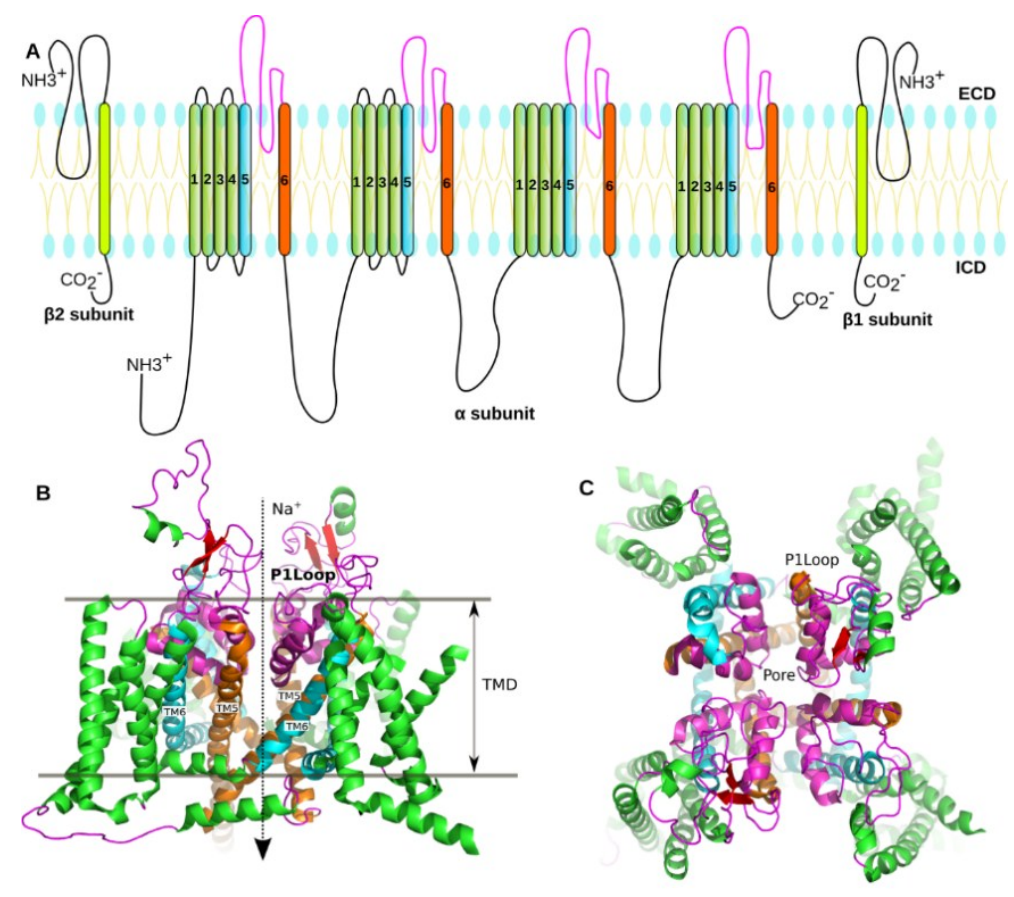

Figure 1. Structure of the voltage-gated sodium channel. (A) The topology of the eukaryotic $\mathrm{Na}_{\mathrm{V}}$ channel. The voltage-sensing domains (VSDs) comprise four repeated segments (1-4) were colored in green. The segments 5 and 6, as well as the sequence between TM5 and TM6 (P1 loop) (Display in the $\mathbf{B})$, that enclose to form the pore domain of the $\mathrm{NaV}$ were colored in cyan, orange, and magenta, respectively; (B) The cryo-EM structure of a eukaryotic $\mathrm{Na}_{\mathrm{V}}$ channel (PDB code: 5XOM). The structure contains four voltage-sensing domains and one pore domain. TMD represents transmembrane domain, while TM5 and TM6 represent the segments 5 and 6 of transmembrane domain; (C) Crystal structure of the prokaryotic sodium channel from Magnetococcus marinus (NaVMs) (PDB code: 4OXS). The structure of the $\mathrm{Na}_{\mathrm{V}} \mathrm{Ms}$ was colored according to the topology of the eukaryotic $\mathrm{Na}_{\mathrm{V}}$ channel. 


\subsection{Conotoxins}

Conotoxins are short disulfide-rich peptide toxins comprising 12-30 amino acid residues and possess varied selectivity on ion channels [9]. $\mu$-Conotoxins are selective and active blockers of the voltage-gated sodium channels. The $\mu$-conotoxin PIIIA was isolated from Conus purpurascens, an Eastern Pacific fish hunting species of cone snails [10]. The PIIIA possesses varied potency towards TTX sensitive $\mathrm{Na}_{\mathrm{V}}$ channels [11,12], and therefore the PIIIA serves as a valuable probe to distinguish $\mathrm{Na}_{V}$ channel subtypes when used in conjunction with other selective toxins [11,13] (Figure 2).

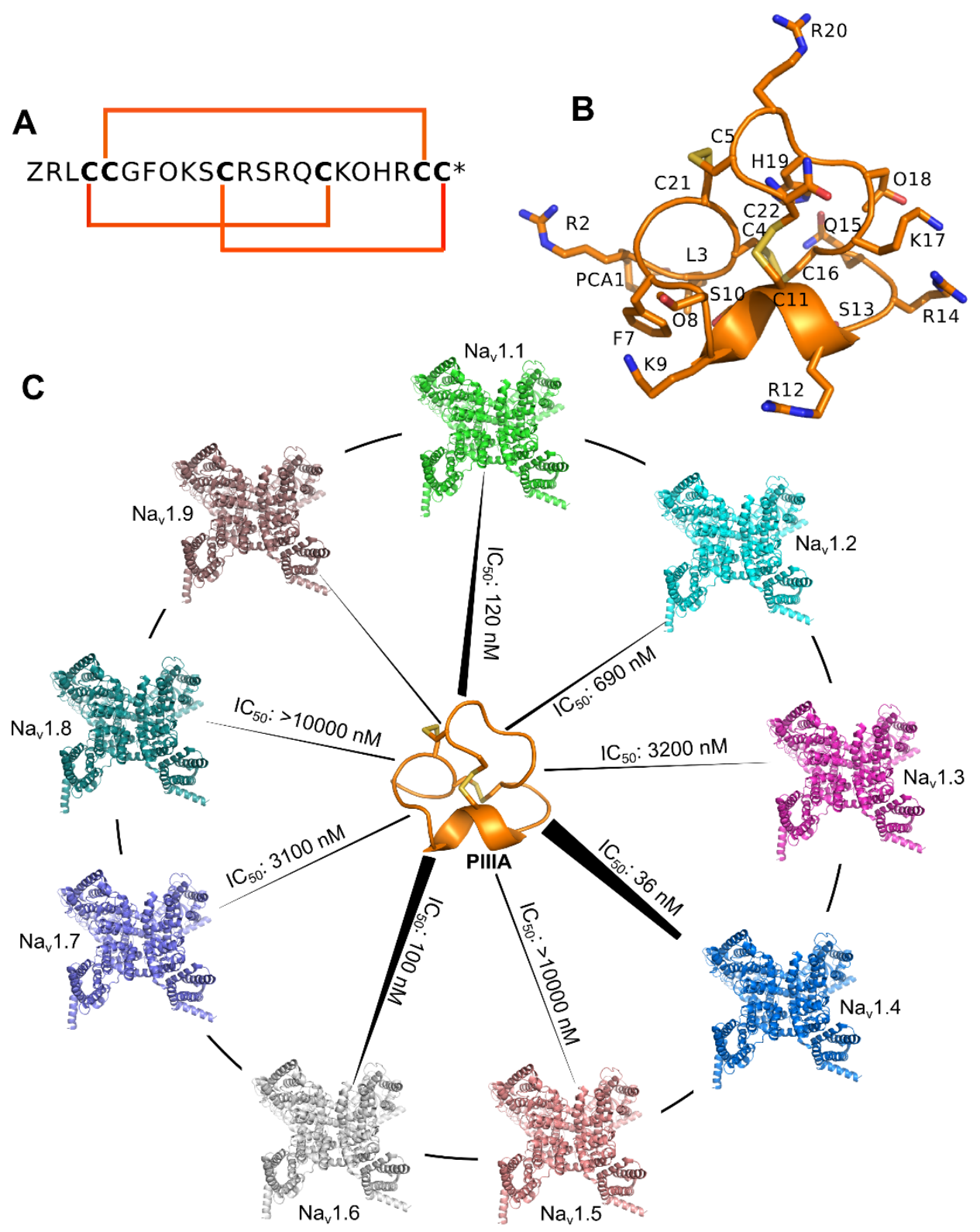

Figure 2. Sequence, structure and function of $\mu$-conotoxin PIIIA. (A) Sequence of the PIIIA, the 6 bold characters " $C$ " represent cysteine residues allowing the formation of three disulfide bonds; (B) Nuclear magnetic resonance (NMR) structure of the PIIIA (PDB Code: 1R9I); (C) Varied specificity of PIIIA to different subtypes of the $\mathrm{Na}_{V}$.

Without the high-resolution crystal structure of the eukaryotic voltage-gated sodium channel, crystal structures of the prokaryotic sodium channel $\mathrm{Na}_{\mathrm{V}} \mathrm{Ab}$ have been widely used as templates to model the interactions between $\mu$-conotoxins and $\mathrm{Na}_{\mathrm{V}} 1.4[14,15]$. These models were used to predict 
the binding affinities of $\mu$-conotoxins against $\mathrm{Na}_{\mathrm{V}} 1.4$, and explained their interaction mechanism [14,15]. However, the molecular determinants that confer the specificity of the $\mu$-conotoxins to varied $\mathrm{Na}_{\mathrm{V}}$ subtypes are still elusive, and no effective computational methodologies are available to predict the specificity of the $\mu$-conotoxins.

In this study, the molecular determinants that confer the specificity of PIIIA to varied subtypes $\left(\mathrm{hNa}_{\mathrm{V}}\right.$ 1.1-1.9) of the $\mathrm{Na}_{\mathrm{V}}$ were determined through extensive molecular dynamics simulations and binding energy calculations. And a computational method that could be used to predict the specificity of the $\mu$-conotoxin PIIIA against different $\mathrm{Na}_{\mathrm{V}}$ subtypes was proposed.

\section{Methods}

\subsection{Flowchart for Specificity Prediction}

Despite millions of years of divergent evolution between the $\mathrm{Na}_{\mathrm{V}} \mathrm{Ms}$ and eukaryotic sodium channel, they both still possess similar pharmacological profiles to the channel blockers as shown by the functional electrophysiological studies [16]. Indeed, previous computational modeling studies suggested that crystal structure of $\mathrm{NaChBac}(\mathrm{Na}(+)$-selective channel of bacteria) could be used as template to model the pore domain of the human or rat $\mathrm{Na}_{V} 1.4$ due to the relatively high sequence identity and structural similarity at the SF domain of the channel. In this study, the crystal structure of the $\mathrm{Na}_{V} \mathrm{Ms}$ in open (PDB code $4 \mathrm{CBC}$ ) was used as template to model the pore domain of the human $\mathrm{Na}_{V}$ 1.4. After building the homology model of $\mathrm{Na}_{V} 1.4$, the NMR structure of the PIIIA (PDB code 1R9I) was docked into the extracellular pore domain of the $\mathrm{Na}_{\mathrm{V}} 1.4$ model [17]. Ten conformations of the PIIIA with minimum docking score were maintained and subjected to further molecular dynamics (MD) refinement and binding energy calculations using MMGB/SA method. The Molecular Mechanics/Poisson Boltzmann Surface Area (MM/PBSA) and Molecular Mechanics/Generalized Born Surface Area (MM/GBSA) approaches are more computationally efficient which estimate protein-protein binding free energies. Conformations of the PIIIA at $\mathrm{Na}_{\mathrm{V}} 1.4$ were ranked based on the binding energies calculated using MMGB/SA. And relatively higher energy conformations of the PIIIA at $\mathrm{Na}_{\mathrm{V}} 1.4$ were discarded, whereas the low energy conformations were maintained and further validated based on the known mutagenesis data $[10,11]$. Once the determined binding mode of PIIIA prokaryotic Nav1.4 was validated by the experimental data, it could be used as template to model interactions of PIIIA with other $\mathrm{Na}_{\mathrm{V}}$ subtypes.

The binding modes of PIIIA against Nav1.x $(x=1,2,3,5,6,7,8,9)$ were determined based on homology modeling using PIIIA/Na 1.4 as the template. The produced models were further refined using MD simulations. The binding energies of PIIIA against $\mathrm{Na}_{V} 1 . x(x=1,2,3,5,6,7,8,9)$ were calculated using MMGB/SA method and umbrella sampling. The final step is the analysis of the correlation between the calculated and experimental derived binding affinities. The flowchart for PIIIA specificity prediction was summarized in Figure 3.

\subsection{Homology Modeling of the $N a_{V} 1.4$}

Models of the $\mathrm{Na}_{\mathrm{V}} 1.4$ were built using the crystal structure of prokaryotic $\mathrm{Na}_{\mathrm{V}} \mathrm{Ms}$ channel (PDB code: 4P9O) as template in MODELLER (version 9v12) [18,19], as described previously [20]. The sequence of $\mathrm{Na}_{\mathrm{V}} 1.4$ was retrieved from the UniProt database [21], and was divided into four homologue sequence fragments based on the sequence of prokaryotic $\mathrm{Na}_{\mathrm{V}} \mathrm{Ms}$. The sequence alignment between the four homologue sequence fragments of $\mathrm{Na}_{\mathrm{V}} 1.4$ and sequence of the prokaryotic $\mathrm{Na}_{\mathrm{V}} \mathrm{Ms}$ (Figure S1) was used to build 100 homology models of the Nav1.4, and the model with the lowest dope score [22] was selected for PIIIA docking. 


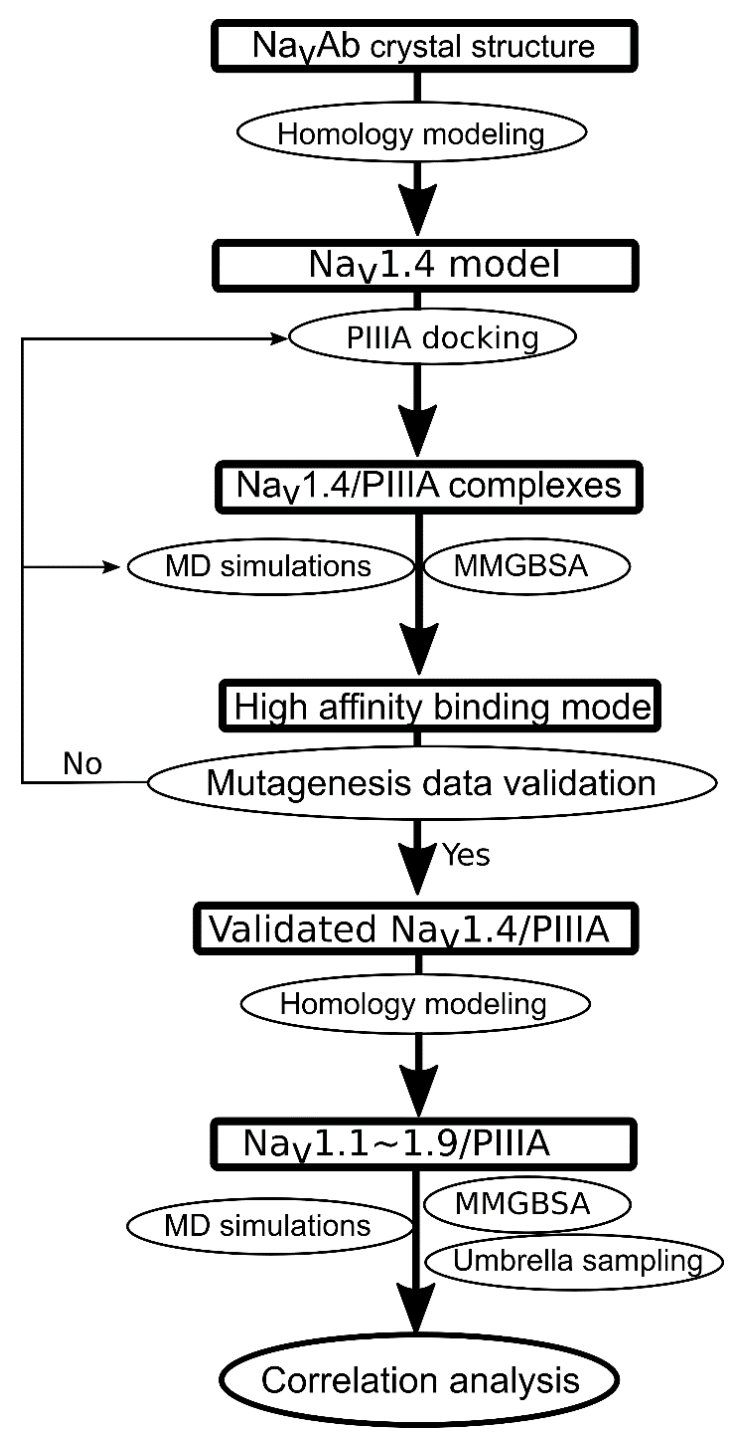

Figure 3. Flowchart for prediction of the specificity of the $\mu$-conotoxin PIIIA to varied $\mathrm{Na}_{V}$ subtypes.

\subsection{PIIIA Docking}

Docking the NMR structure of PIIIA (PDB Code: 1R9I) to Nav1.4 model was performed using AutoDock 4.2 [23]. Gasteiger charges were used, and nonpolar hydrogens of the macromolecule and ligand were merged. A grid box with dimensions of $60 \AA \times 60 \AA \times 60 \AA$ and a grid spacing of $0.375 \AA$ was set up and centered on the geometry center of the "P1 loop" of the four domains. Docking was performed using a Lamarckian genetic algorithm (LGA), with the receptor treated as rigid, the docking results were analyzed by AutoDock Tools. The produced conformations with top 10 docking score were selected for the MD refinement.

\subsection{Restraint Molecular Dynamics Simulations}

The selected $10 \mathrm{Na}_{\mathrm{V}} 1.4 / \mathrm{PIIIA}$ complexes were subjected to MD simulations for refinement of the PIIIA binding mode in AMBER 16 [24]. The MD simulations are performed using the ff14SB force field for the proteins and the peptide [25]. Parameters for the pyroglutamic acid (PCA) residue were prepared using the antechamber module in AMBER 16. Atom partial charges for PCA (pyroglutamic acid) were produced using the R.E.D Tools [26]. The PCA was incorporated into the PIIIA peptide as an unnatural amino acid. After building the whole system in LEaP that is a module of AMBER16, minimization was performed to remove the van der Waals clashes between PIIIA and Nav1.4. The 2000 steps of 
steepest descent minimization and 3000 conjugate gradient minimum were performed with the solute restrained using a harmonic force potential with a spring constant of $100 \mathrm{kcal} / \mathrm{mol}^{-1} / \AA^{-2}$. After the first round of minimization, the restraints were withdrawn and the whole system was minimized using the same parameters as above. MD simulations were carried out after minimization. First, the whole system was gradually heated from $50 \mathrm{~K}$ to $300 \mathrm{~K}$ at constant volume and temperature ensemble for $100 \mathrm{ps}$ with the solute restrained with a harmonic force of $5 \mathrm{kcal} / \mathrm{mol}^{-1} / \AA^{-2}$. The simulations were then switched to constant pressure and temperature ensemble by maintaining the harmonic restraints in 100 ps. For the production run, the restraints on PIIIA as well as the P1 loop were withdrawn and $20 \mathrm{~ns}$ MD simulations were performed with the temperature and pressure maintained at $300 \mathrm{~K}$ and 1 bar, respectively. All bonds involving hydrogen atoms were constrained with the SHAKE algorithm with a time step of 2 fs [27]. The particle-mesh Ewald (PME) method was used to model long-range electrostatic interactions [28]. The following MD simulations on PIIIA/ $\mathrm{Na}_{\mathrm{V}} 1 . x(\mathrm{x}=1,2,3,5,6,7,8,9)$ used the same parameters setting up as PIIIA/Nav1.4 system.

\subsection{Molecular Dynamics Simulation of the $\mathrm{Na}_{V} 1.4$ in Membrane}

For evaluation of the membrane influences on the conformation of the $\mathrm{Na}_{\mathrm{V}} 1.4$ and the bound PIIIA, MD simulations were performed on $\mathrm{Na}_{\mathrm{V}} 1.4$ in apo and in complex with PIIIA. The $\mathrm{Na}_{\mathrm{V}} 1.4$ in apo or bound with PIIIA were inserted a bilayer containing a 2:2:1 mixture of POPC (1-palmitoyl-2-oleoyl-sn-glycero-3-phosphocholine):POPE (1-palmitoyl-2-oleoyl-sn-glycero3-phosphoethanolamine):Cholesterol as suggested in previous study [29] with dimension of $80 \times 80 \times 80 \AA^{3}$ and the system solvated with TIP3P [30] water molecules and $\mathrm{Na}^{+}$and $\mathrm{Cl}^{-}$ions such that the system was neutral with an overall concentration of $0.15 \mathrm{M}$ in CHARMM-GUI that is a webserver for preparing MD simulation system (http:/ / www.charmm-gui.org). The temperature of the system was gradually increased to $310 \mathrm{~K}$ and was equilibrated for 500 ps in NVT (constant-volume, constant-temperature) and NPT (constant-pressure, constant-temperature) ensembles, respectively, with the protein and lipids restrained with $10 \mathrm{kcal} / \mathrm{mol} / \AA^{2}$ force. Langevin thermostat is used for the initial heating. For the second phase heating, an anisotropic Berendsen weak-coupling barostat is used to equilibrate the pressure in addition to the use of the Langevin thermostat to equilibrate the temperature. Then, the restraint of the membrane was withdrawn and the whole system was simulated for $20 \mathrm{~ns}$ in NPT for properly equilibrating the membrane system. And the restraint on the protein was gradually withdrawn in 10 steps in $5 \mathrm{~ns}$ MD simulations. Afterwards, 150 ns production run was performed on the $\mathrm{Na}_{\mathrm{V}} 1.4$ in apo and in complex with PIIIA, respectively. In production run, the temperature was controlled using the Langevin thermostat while pressure was controlled using the anisotropic Berendsen barostat. All simulations were performed using the Lipid14 force field [31] for the lipid, AMBER14SB force field for the protein [31]. The MD simulations used a time step of $2 \mathrm{fs}$ and, all bonds involving hydrogen atoms were maintained to their standard length using the SHAKE algorithm [32]. Particle Mesh Ewald (PME) [33] was used with a cutoff of $10 \AA$ for non-bonded atoms interactions and neighbor lists were updated every 10 steps.

\subsection{Binding Energy Calculations Using MMGB/SA}

Molecular mechanics generalized Born surface area (MMGB/SA) [34] were applied to calculate the binding affinities of PIIIA against the $\mathrm{Na}_{\mathrm{V}}$ channels. The energies were averaged on the 50 frames extracted from the last $10 \mathrm{~ns}$ MD simulations. The parameters are as previously reported [20]. Briefly, the internal dielectric and external dielectric constants were set to 2.0 and 80.0, respectively. A probe radius of $1.4 \AA$, a grid spacing of $0.5 \AA$ and ionic strength $0.1 \mathrm{~mol} / \mathrm{L}$ were set up for the calculations.

\subsection{Decomposition of the Binding Energies}

The binding energies calculated using MMGB/SA were decomposed into energy contributions from each residue of the binding site using the MMPB/SA.py script in AMBER16. Parameters setting up was the same as above. 


\subsection{Binding Energies Calculations Using Umbrella Sampling}

Umbrella sampling is one biased MD method that provides free energy along a reaction coordinate [35]. In umbrella sampling, a bias potential is applied to drive a system from one thermodynamic state to another along a reaction coordinate. Here, the distance between the center of mass of the PIIIA and the center of mass of the five symmetric CA atoms in the transmembrane domain were selected as the reaction coordinate, and along which a harmonic potential was added (Equation (1)).

$$
\mathrm{F}(\mathrm{x})=\mathrm{k}\left(\mathrm{x}-\mathrm{x}_{0}\right)^{2}
$$

where the $\mathrm{k}$ is $100 \mathrm{kcal} / \mathrm{mol} / \AA^{2}$ and $\mathrm{x}_{0}$ is the initial distance.

When the reaction coordinate $\left(x-x_{0}\right)$ reached $15 \AA$, the PIIIA was considered completely unbound from the channel. The reaction coordinate was divided into 30 windows, and in each window, $2 \mathrm{~ns} M D$ simulations were performed. The windows were then combined by the weighted histogram analysis method (WHAM) [36]. Conformations in the last $1.5 \mathrm{~ns}$ were used to derive the potential of mean force along the coordinate using WHAM. The binding/unbinding free energy of PIIIA was calculated using the PMF values at the end of unbinding.

\section{Results and Discussion}

\subsection{Prediction of the Binding Mode of the PIIIA at $\mathrm{Na} a_{V} 1.4$}

$\mu$-Conotoxin PIIIA was positioned on the pore surface of the extracellular domain of Nav1.4 based on docking. During docking, the top 10 conformations were retained (Figure S2) for MD refinement and binding energy calculations. The PIIIA was positioned at the surface of the Nav1.4 with varied conformations (Figure S2A,B). The binding energies predicted using Autodock are considerably higher than the experimental values. The unfavorable binding energies given by the docking technique are originated from the poor accuracy when dealing with the flexibility of the protein and the peptide by AutoDock. During docking, only side chains of the PIIIA were considered as flexible, whereas side chains of the $\mathrm{Na}_{\mathrm{V}} 1.4$ were considered as rigid. As a consequence, the predicted binding affinities were underestimated using docking. Thus, it is prerequisite to refine the binding mode of PIIIA at Nav1.4 using MD, and re-rank the binding affinities of PIIIA at $\mathrm{Na}_{\mathrm{V}} 1.4$ using more rigorous energy estimation method, like MMGB/SA or MMPB/SA.

Here, the MMGB/SA method was used to calculate the binding affinities of the 10 conformations of PIIIA at $\mathrm{Na}_{\mathrm{V}} 1.4$ due to its slightly better performance than MMPB/SA method to rank the binding affinities of the $\alpha$-conotoxin analogues in a previous study [20]. The ranking order for the 10 conformations significantly changed after re-ranking based on the MMGB/SA method (Table S1), and their backbone orientation at the binding site of $\mathrm{Na}_{\mathrm{V}} 1.4$ in some cases significantly varied (Figure S3). Conformation for the side chains of PIIIA varied significantly after MD simulations in most cases (not shown).

Conformations of PIIIA with optimum binding energy were selected for accuracy validation by comparison with the mutagenesis data [37]. We found that the minimum binding energy conformation of PIIIA was the most consistent with the mutagenesis data, and its binding mode to $\mathrm{Na}_{\mathrm{V}} 1.4$ was shown in Figure 3. The PIIIA was positioned at the pore surface of the ECD with the axis of the helix between residue 6 and 15 tilted to the pore, resulting in the N-termini outward tilted from the binding site forming no direct interactions with residues of the binding site. The predicted binding mode of PIIIA is consistent with the previously determined binding mode of PIIIA at the Nav 1.4 using restraint docking method [14]. The PIIIA is rich with positively charged residues, whereas the binding site of $\mathrm{Na}_{V} 1.4$ possesses an abundance of negatively charged residues (Figure S4). Thus, the net charge of the PIIIA is overall complementary to the $\mathrm{Na}_{\mathrm{V}}$ 1.4. Indeed, there are numerous salt-bridges formed at the interface between PIIIA and $\mathrm{Na}_{\mathrm{V}} 1.4$ (Figure 4). The R14 and K17 of PIIIA form salt-bridges with E755 and D1241, two of the filter residues at the pore domain, respectively. The R12 of PIIIA forms salt-bridges with E758 that is near the pore filter, while the R20 forms salt-bridges with D1541 at the 
periphery of the binding site. Besides, the hydroxyl group of $\mathrm{O} 18$ forms a pair of hydrogen bonds with N1536. Thus, our predicted binding mode of PIIIA against the Nav1.4 suggests that the salt-bridges as well as the hydrogen bonds are the dominant binding determinants for PIIIA binding to Na 1.4 . Indeed, the previous mutagenesis data also supports that R14, R12, K17, and R20 contribute most to the binding affinity of PIIIA to $\mathrm{Na}_{V} 1.4$ [37]. More detailed pairwise interactions between PIIIA and Nav1.4 were listed in Table 1.

Table 1. Key pairwise interacting residues from PIIIA and binding site of the $\mathrm{Na}_{\mathrm{V}} 1.1$ to $\mathrm{Na}_{\mathrm{V}} 1.9$.

\begin{tabular}{|c|c|c|c|c|c|c|}
\hline $\mathrm{Nav}$ & $\mathrm{R}^{12}{ }^{\mathrm{a}}$ & $\mathrm{R} 14^{\mathrm{a}}$ & $\mathrm{Q15}^{\mathrm{a}}$ & $\mathrm{K} 17^{\mathrm{a}}$ & $018^{a}$ & $\mathrm{R}^{2} 0^{\mathrm{a}}$ \\
\hline $\mathrm{Na}_{\mathbf{V}} 1.1$ & E758, W761 & F401, N404, E755 & L408 & - & N404, D1533 & A1536, D1541 \\
\hline Nav1.2 & E758, W761 & F401, N404, E758 & L408 & D1241 & N404, D1533 & A1536, D1541 \\
\hline $\mathrm{Na}_{V} 1.4$ & E758, W761 & F401, N404, E755, E758 & L408 & D1241 & N404, D1533, N1536 & D1541 \\
\hline $\mathrm{Na}_{V} 1.5$ & W761 & E755, E758 & Q408 & - & R404 & D1541 \\
\hline Nav1.6 & E758, W761 & Y401, N404, E755 & L408 & - & R1533 & L1536, D1541 \\
\hline Nav1.9 & W761 & E755, E758 & $\widehat{\mathrm{Q}} 408$ & - & D1532, S1536 & N1541 \\
\hline
\end{tabular}

${ }^{a}$ Residues of the $\mathrm{Na}_{\mathrm{V}}$ within $4 \AA$ from the key residues of PIIIA were listed in the table.

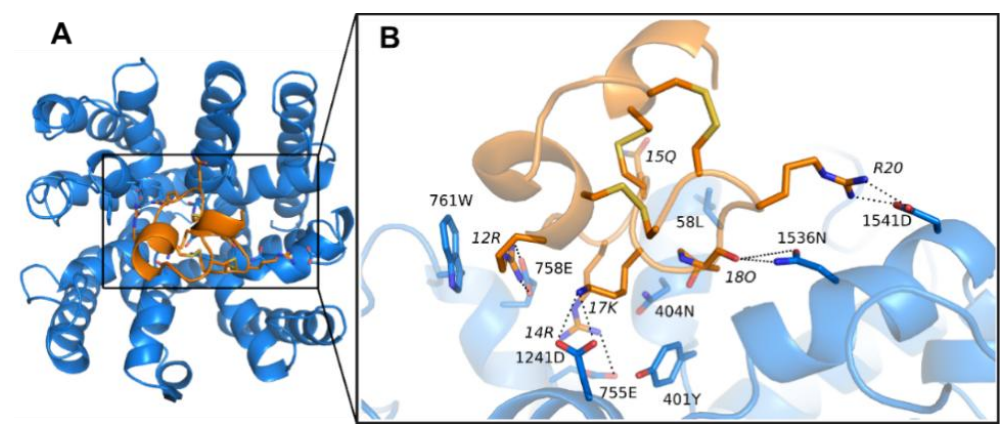

Figure 4. The binding modes of $\mu$-conotoxin PIIIA at Nav1.4. The PIIIA and Nav1.4 were colored in orange and blue, respectively. The dashed lines show the hydrogen bonds or salt bridges. (A) The binding modes of Na 1.4 /PIIIA; (B) The magnified show of the binding modes of Na $1.4 / \mathrm{PIIIA}$ in binding box.

\subsection{Influences of the Membrane to the Conformation of the $N a_{V} 1.4$ in apo and $N a_{V} 1.4$ in Complex with PIIIA}

For consideration of the influences of the membrane to the conformation of $\mathrm{Na}_{V} 1.4$ and PIIIA/ Na 1.4 complex model, nonrestraint molecular dynamic simulations were performed on the $\mathrm{Na}_{\mathrm{V}} 1.4$ model in apo or in complex with PIIIA embedded in the membrane. MD simulations results suggest that conformation of the $\mathrm{Na}_{\mathrm{V}} 1.4$ model in apo and in complex with PIIIA is stable in $100 \mathrm{~ns}$ MD. The RMSD (root-mean-square deviation) value of the Nav1.4 model in complex with PIIIA is lower than that in apo (Figure S5A). Obviously, binding PIIIA to Nav1.4 has a stabilization effect on this model. After $150 \mathrm{~ns}$ of non-restraint MD the binding mode of PIIIA at Nav1.4 is essentially the same to that determined using restraint MD without adding the membrane (Figure S5B). Thus, it is applicable to use more efficient restraint MD for the refinement of the binding mode of PIIIA at $\mathrm{Na}_{\mathrm{V}} 1.4$ without incorporation of the membrane.

\subsection{Binding Modes of PIIIA at Other Subtypes of $N a_{V}$}

PIIIA possesses broad inhibitory spectra on $\mathrm{Na}_{V}$, from $\mathrm{Na}_{V} 1.1$ to $\mathrm{Na}_{\mathrm{V}} 1.8$ [10-12,38-40]. Residues at the binding site of the $\alpha$ subunit of $\mathrm{Na}_{\mathrm{V}}$ is highly conserved, and it might be applicable to homology model the binding modes of PIIIA to $\mathrm{Na}_{\mathrm{V}} 1 . \mathrm{x}(\mathrm{x}=1,2,3,5,6,7,8,9)$ by using PIIIA/Na 1.4 as the template. In this study, the PIIIA was directly modelled into the binding site of $\mathrm{Na}_{\mathrm{V}} 1 . \mathrm{x}$ 
$(\mathrm{x}=1,2,3,5,6,7,8,9)$ using PIIIA/Na 1.4 as a template instead of using the docking method in considering of its incapacity for dealing with the flexibility of the protein and the peptide and its inaccuracy for prediction the binding affinity of the peptide ligands. Then the binding modes of PIIIA to $\operatorname{Na}_{V} 1 . x(x=1,2,3,5,6,7,8,9)$ were refined using MD simulations.

Binding modes of PIIIA to Nav1.x $(x=1,2,3,5,6,7,8,9)$ are essentially the same to Nav1.4 (Figure 5). However, some of the key pairwise interactions at PIIIA/Nav1.4 are absent at PIIIA/Nav1.x $(x=2,3,5,7,8)$, whereas they are all conserved at PIIIA/Nav1. $x(x=1,6)$. Because of presence of all these key pairwise interactions at PIIIA/Nav1.x $(x=1,6)$, the PIIIA possesses comparable inhibitory activity between $\mathrm{Na}_{V} 1 . x(x=1,6)$ and $\mathrm{Na}_{V} 1.4$. By contrast, one to three of the key pairwise interactions were absent at PIIIA/ $\mathrm{Na}_{V} 1 . x(x=2,3,5,7,8)$, which might explain the insensitivity of these $\mathrm{Na}_{\mathrm{V}}$ subtypes to PIIIA. More detailed pairwise interactions between PIIIA and $\mathrm{Na}_{\mathrm{V}} 1 . \mathrm{x}(\mathrm{x}=1,2,3,5,6,7,8,9)$ are shown in Table 1 .

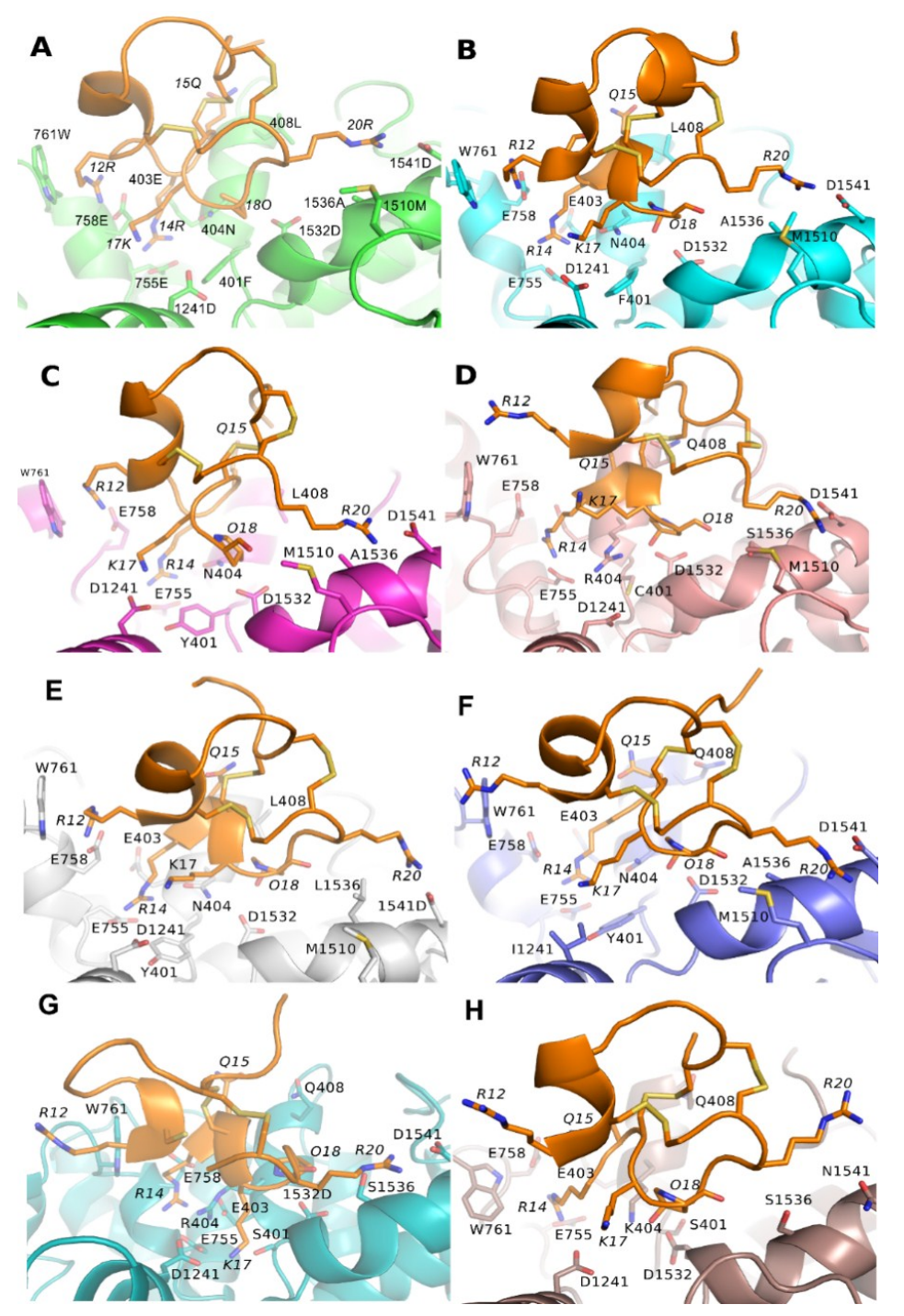

Figure 5. Binding modes of PIIIA at different $\mathrm{Na}_{\mathrm{V}}$ subtypes. The PIIIA was shown in orange, and binding site of varied $\mathrm{Na}_{V}$ subtype from $\mathrm{Na}_{\mathrm{V}} 1.1$ to $\mathrm{Na}_{\mathrm{V}} 1.9$ was colored in green $\left(\mathrm{Na}_{\mathrm{V}} 1.1\right)$, cyan $\left(\mathrm{Na}_{V} 1.2\right)$, magenta $\left(\mathrm{Na}_{V} 1.3\right)$, light pink $\left(\mathrm{Na}_{V} 1.5\right)$, gray $\left(\mathrm{Na}_{V} 1.6\right)$, blue $\left(\mathrm{Na}_{V} 1.7\right)$, teal $\left(\mathrm{Na}_{V} 1.8\right)$ and chocolate $\left(\mathrm{Na}_{\mathrm{V}} 1.9\right)$. Residues at PIIIA were labeled in italics. For clarity, the hydrogen bonds were not shown. (A) Binding modes of Na $1.1 /$ PIIIA; (B) Binding modes of Na $1.2 /$ PIIIA; (C) Binding modes of $\mathrm{Na}_{\mathrm{V}} 1.3 / \mathrm{PIIIA}$; (D) Binding modes of Na $1.5 /$ PIIIA; (E) Binding modes of Na $1.6 / \mathrm{PIIIA}$; (F) Binding modes of $\mathrm{Na}_{\mathrm{V}} 1.7 /$ PIIIA; $(\mathbf{G})$ Binding modes of $\mathrm{Na}_{\mathrm{V}} 1.8 /$ PIIIA; $(\mathbf{H})$ Binding modes of $\mathrm{Na}_{\mathrm{V}} 1.9 /$ PIIIA. 


\subsection{Prediction of the Specificity of PIIIA to Varied NaV Subtypes}

Prediction of the specificity of PIIIA to different $\mathrm{Na}_{\mathrm{V}}$ subtypes presents a challenge, as it involves in differentiation of the binding affinity of PIIIA to several highly conserved Nav subtypes. In this study, we used two computational methods, MMGB/SA and umbrella sampling to predict the binding affinities of PIIIA to $\mathrm{Na}_{V}$ subtypes from $\mathrm{Na}_{V} 1.1$ to $\mathrm{Na}_{V} 1.9$.

The MMGB/SA was used to predict the binding affinities of PIIIA to varied $\mathrm{Na}_{\mathrm{V}}$ subtypes due to its better performance than MMPB/SA at ranking the binding affinities of $\alpha$-conotoxin analogues in our previous study [21]. For sufficiently sampling the conformation of PIIIA at varied $\mathrm{Na}_{\mathrm{V}}$ subtypes, the top three DOPE score PIIIA/ $\mathrm{Na}_{\mathrm{V}} 1 . x(\mathrm{x}=1,2,3,5,6,7,8,9)$ models were selected for MD simulations, and $20 \mathrm{~ns}$ MD simulations were performed on each of the PIIIA/Nav1.4 systems. Frames from the last $10 \mathrm{~ns}$ MD were used to calculate the binding energy using MMGB/SA method. The calculated binding affinities were averaged on the three MD trajectories for each of PIIIA/ $\mathrm{Na}_{\mathrm{V}} 1 . \mathrm{x}(\mathrm{x}=1,2,3,4$, $5,6,7,8,9)$ systems. In a previous study, we found that incorporation of the entropy component to the G-free energy gave slightly worse ranking of the binding affinity of the $\alpha$-conotoxin analogues despite of the significantly increased consumption of the computational resources [21]. Thus, only the enthalpy rather than the entropy was calculated and used for ranking the binding affinity of PIIIA to varied $\mathrm{Na}_{\mathrm{V}}$ subtypes. As shown by Table 2, the predicted binding energies without entropy using MMGB/SA are much lower than the experimental values, whereas they are modestly correlated with the experimental values giving a correlation coefficient of $0.41\left(R^{2}\right)$ (Figure 6). Thus, MD simulations coupling of MMGB/SA energy calculation could give modestly accurate predictions of the specificity of PIIIA to varied $\mathrm{Na}_{\mathrm{V}}$ subtypes.

The umbrella sampling is more efficient than MD simulations for conformation sampling, and it has been frequently applied to predict the binding free energies of the conotoxins to their target proteins [41-46]. In this study, umbrella sampling was used to predict the binding affinities of PIIIA against varied $\mathrm{Na}_{\mathrm{V}}$ subtypes. The above MD refined the top three models of the PIIIA/ $\mathrm{Na}_{\mathrm{V}}$ systems, and were used as the initial for umbrella sampling simulations. The predicted binding free energies of PIIIA against varied $\mathrm{Na}_{\mathrm{V}}$ subtypes were derived from the calculation of potential of mean force (PMF) and were shown in Table 2. The absolute values of the predicted binding free energies using umbrella sampling are quite similar to the experimental values, and are high correlated to the experimental values with a correlation efficient of $0.68\left(\mathrm{R}^{2}\right)$. Thus, umbrella sampling could give a highly accurate ranking of the inhibition activity of PIIIA to different $\mathrm{Na}_{\mathrm{V}}$ subtypes. Umbrella sampling gave a better prediction of the specificity of PIIIA to varied $\mathrm{Na}_{\mathrm{V}}$ subtypes due to its more efficient conformation sampling.

Table 2. Calculated binding affinities of PIIIA to varied $\mathrm{Na}_{\mathrm{V}}$ subtypes from $\mathrm{Na}_{V} 1.1$ to $\mathrm{Na}_{\mathrm{V}} 1.9$.

\begin{tabular}{|c|c|c|c|c|}
\hline $\mathrm{Na}_{\mathbf{V}}$ & $\mathrm{IC}_{50}$ & $\mathrm{MMGB}_{\mathrm{SA}}{ }^{\mathrm{a}}$ & Umbrella Sampling ${ }^{b}$ & Experimental (kcal/mol) $^{c}$ \\
\hline $\mathrm{Na}_{\mathrm{V}} 1.1$ & $120 \mathrm{~nm}$ & $-46.81 \pm 2.61$ & $-11.97 \pm 0.78$ & -9.40 \\
\hline $\mathrm{Na}_{V} 1.2$ & $620 \mathrm{~nm}$ & $-46.36 \pm 4.94$ & $-12.99 \pm 1.21$ & -8.43 \\
\hline $\mathrm{Na}_{V} 1.3$ & $3.2 \mu \mathrm{m}$ & $-41.74 \pm 1.08$ & $-11.93 \pm 0.87$ & -7.46 \\
\hline $\mathrm{Na}_{V} 1.4$ & $36 \mathrm{~nm}$ & $-41.82 \pm 4.61$ & $-16.81 \pm 0.49$ & -10.11 \\
\hline $\mathrm{Na}_{V} 1.5$ & $10 \mu \mathrm{m}$ & $-37.83 \pm 2.88$ & $-8.09 \pm 1.44$ & -6.79 \\
\hline $\mathrm{Na}_{V} 1.6$ & $100 \mathrm{~nm}$ & $-44.01 \pm 1.51$ & $-18.95 \pm 1.02$ & -9.51 \\
\hline $\mathrm{Na}_{V} 1.7$ & $>10 \mu \mathrm{m}$ & $-42.53 \pm 1.86$ & $-7.94 \pm 1.80$ & -7.48 \\
\hline $\mathrm{Na}_{V} 1.8$ & $>10 \mu \mathrm{m}$ & $-38.00 \pm 2.55$ & $-10.68 \pm 2.84$ & -7.07 \\
\hline $\mathrm{Na}_{\mathrm{V}} 1.9$ & - & $-29.24 \pm 5.03$ & $-9.41 \pm 2.01$ & - \\
\hline
\end{tabular}

a The binding affinities of PIIIA to varied $\mathrm{Na}_{\mathrm{V}}$ subtypes were calculated using MMGB/SA method. Twenty MD simulations were performed on the top 3 PIIIA/ $\mathrm{Na}_{\mathrm{V}}$ models from homology modeling. The MMGB/SA calculation was performed on the last $10 \mathrm{~ns}$ of the five MD trajectories; ${ }^{\mathrm{b}}$ The binding affinities of PIIIA were calculated using umbrella sampling (US) on the top 3 PIIIA/Nav models; ${ }^{c}$ Binding affinities of PIIIA were derived from the IC $_{50}$ of PIIIA to varied $\mathrm{Na}$ v subtypes from $\mathrm{Na}_{\mathrm{V}} 1.1$ to $\mathrm{Na}_{\mathrm{V}} 1.9$ using $\Delta \mathrm{G}=-\mathrm{RT} \ln \left(\mathrm{IC}_{50}\right)$. 
A

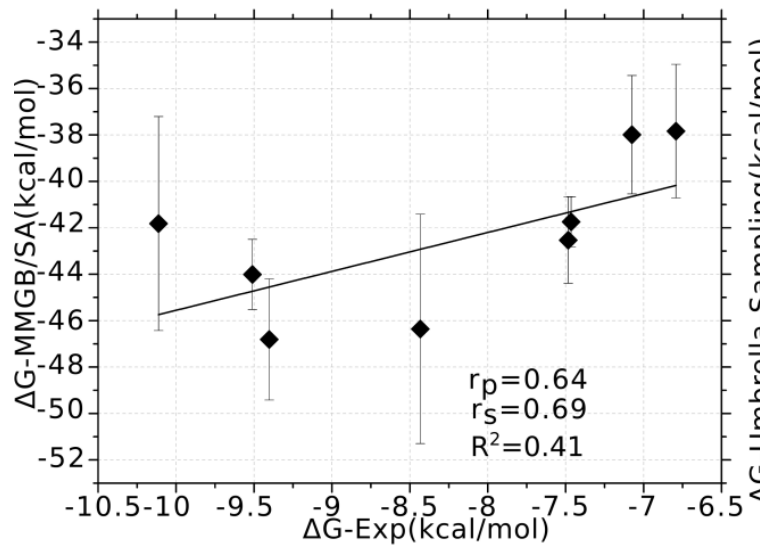

B

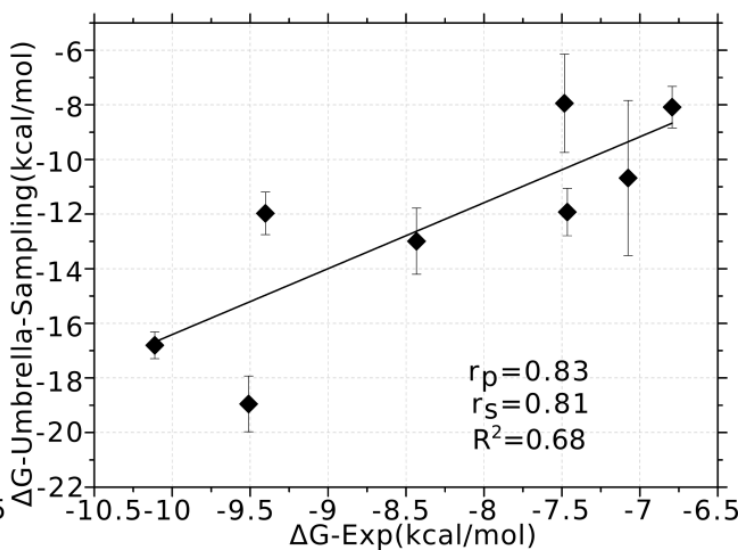

Figure 6. Correlation between the binding energies derived from experiment and calculated using MM/GBSA and umbrella sampling. (A) The binding affinity of PIIIA to varied $\mathrm{Na}_{V}$ subtypes was calculated using MMGB/SA method based on three MD trajectories of the top three models; (B) the binding affinity of PIIIA to varied $\mathrm{Na}_{\mathrm{V}}$ subtypes was calculated using umbrella sampling on the top three models. The Pearson relation coefficient $\left(r_{p}\right)$ and Spearman relation coefficient $\left(r_{s}\right)$ were used to characterize the correlation between the calculated binding affinities and experimentally derived values.

There is no binding or $\mathrm{IC}_{50}$ data for PIIIA to $\mathrm{Na}_{\mathrm{V}} 1.9$. Binding energies calculation from both MMGB/SA and umbrella sampling together predict that PIIIA possesses poor binding affinity to the $\mathrm{Na}_{V} 1.9$.

\subsection{Binding Energy Decomposition Using MMGB/SA}

The binding energy calculated using MMGB/SA was decomposed into energetic contributions from each residue of the binding site (Figure 7 and Table S2). Binding energy decomposition suggests that all residues of the binding site except for D1532 significantly contributes to the binding affinity of PIIIA to $\mathrm{Na}_{V}$. Binding mode analysis suggests that the D1532 locates in the binding site forming van der Waals contacts with the backbone of the PIIIA (Figure 4). The high desolvation energy of D1532 might result in its unfavorable binding to most of the $\mathrm{Na}_{\mathrm{V}}$ subtypes, except for $\mathrm{Na}_{\mathrm{V}} 1.3$ in which the D1532 forms an unstable hydrogen bond with PIIIA O18. An aromatic residue such as Y or F at 401 significantly contributes to the binding affinity of PIIIA to $\mathrm{Na}_{V} 1.1, \mathrm{Na}_{V} 1.2, \mathrm{Na}_{V} 1.3, \mathrm{Na}_{V} 1.4, \mathrm{Na}_{V} 1.6$ and $\mathrm{Na}_{\mathrm{V}}$ 1.7. In our model, the side chain of the aromatic residue at 401 stacks with the side chain of K17, forming favorable van der Waals contacts (Figure 4). By contrast, the C and S merely form few contacts with the side chain of K17, explaining their little energetic contribution to the binding affinity of PIIIA to $\mathrm{Na}_{\mathrm{V}} 1.5, \mathrm{Na}_{\mathrm{V}} 1.8$ and $\mathrm{Na}_{\mathrm{V}} 1.9$. A neutral $\mathrm{N}$ at 404 is more energetically favorable for the binding of PIIIA to Nav1.x $(x=1,2,3,4,6,7)$ than the positively charged $\mathrm{R}$ or $\mathrm{K}$ of Nav1.x $(\mathrm{x}=5,8,9)$. Binding mode analysis indicates that side chain of $\mathrm{N}$ can form a hydrogen bond with R14, whereas this hydrogen bond is absent when a positively charged residue is present at 404 (Figure 4). The $L$ and $Q$ at 408 showed only a little difference to the binding affinity of PIIIA to varied subtypes of $\mathrm{Na}_{V}$, despite of their side chain hydrophobicity difference. The $\mathrm{L}$ and $\mathrm{Q}$ at 408 are at the periphery of the binding site where they both form few van der Waals contacts with the PIIIA explaining their little difference to the binding affinity of PIIIA. The conserved E755 is located at the center of the binding site, substantially contributing to the binding affinity of PIIIA by forming salt bridges with the side chain of R14 with energetic contribution varied from $-4 \mathrm{kcal} / \mathrm{mol}$ to $-7 \mathrm{kcal} / \mathrm{mol}$ (Figure 5). By contrast, the conserved E758 contributes less than E755 to the binding affinity of PIIIA to subtypes of $\mathrm{Na}_{\mathrm{V}}$ by forming an electrostatic interaction with R12 of PIIIA. A conserved aromatic residue, W761, contributes $-2 \sim-1 \mathrm{kcal} / \mathrm{mol}$ binding energy to PIIIA by forming van der Waal contacts with side 
chain of R12. A D at 1241 is conserved among varied subtypes of $\mathrm{Na}_{V} 1$ except for $\mathrm{Na}_{\mathrm{V}} 1.7$, on which an I is present this position. The D1241 locates at the periphery of the binding site where it only contributes $-2 \sim 0 \mathrm{kcal} / \mathrm{mol}$ binding energy to the total binding affinity of PIIIA. The side chain of K17 on PIIIA tilted to the D1241 and could form favorable electrostatic interaction in MD. The D at 1532 is conserved across all Na $\mathrm{V}_{\mathrm{V}}$ subtypes. The D1532 contributes little or even unfavorable binding energy to the binding affinity of PIIIA to different subtypes of $\mathrm{Na}_{\mathrm{V}} 1$ except for to the $\mathrm{Na}_{\mathrm{V}} 1.3$ in which D1532 can form a hydrogen bond with the hydroxyl group of O18. Residues at 1536 are not conserved across different subtypes of $\mathrm{Na}_{\mathrm{V}}$. An $\mathrm{N}$ at 1536 of $\mathrm{Na}_{\mathrm{V}} 1.4$ can form a hydrogen bond with the hydroxyl group of $\mathrm{O} 18$, whereas this hydrogen bond is absent when $\mathrm{A}, \mathrm{S}$ or $\mathrm{L}$ are present at the same position. The side chain of L1536 at Nav1.6 stacks with the side chain of R20 as well as the backbone of PIIIA, and significantly contributes to its binding affinity. A S at 1536 can form hydrogen bond with R20 and significantly contributes to its binding to $\mathrm{Na}_{\mathrm{V}} 1.8$, whereas such pairwise interaction is absent at the $\mathrm{Na}_{V}$ 1.9. Thus, the same residue at the same positions of different subtypes of $\mathrm{Na}_{V}$ might play different roles to the binding affinity of PIIIA. The D at 1541 is conserved across all $\mathrm{Na}_{\mathrm{V}}$ subtypes from $\mathrm{Na}_{\mathrm{V}} 1.1$ to $\mathrm{Na}_{\mathrm{V}} 1.8$, whereas an $\mathrm{N}$ is at the same position of $\mathrm{Na}_{\mathrm{V}} 1.9$. Either an $\mathrm{D}$ or an $\mathrm{N}$ at 1541 of $\mathrm{Na}_{\mathrm{V}}$ subtypes contributes to about $-2 \mathrm{kcal} / \mathrm{mol}$ energy to the binding affinity of PIIIA by forming salt bridges or hydrogen bonds with R20 of PIIIA.

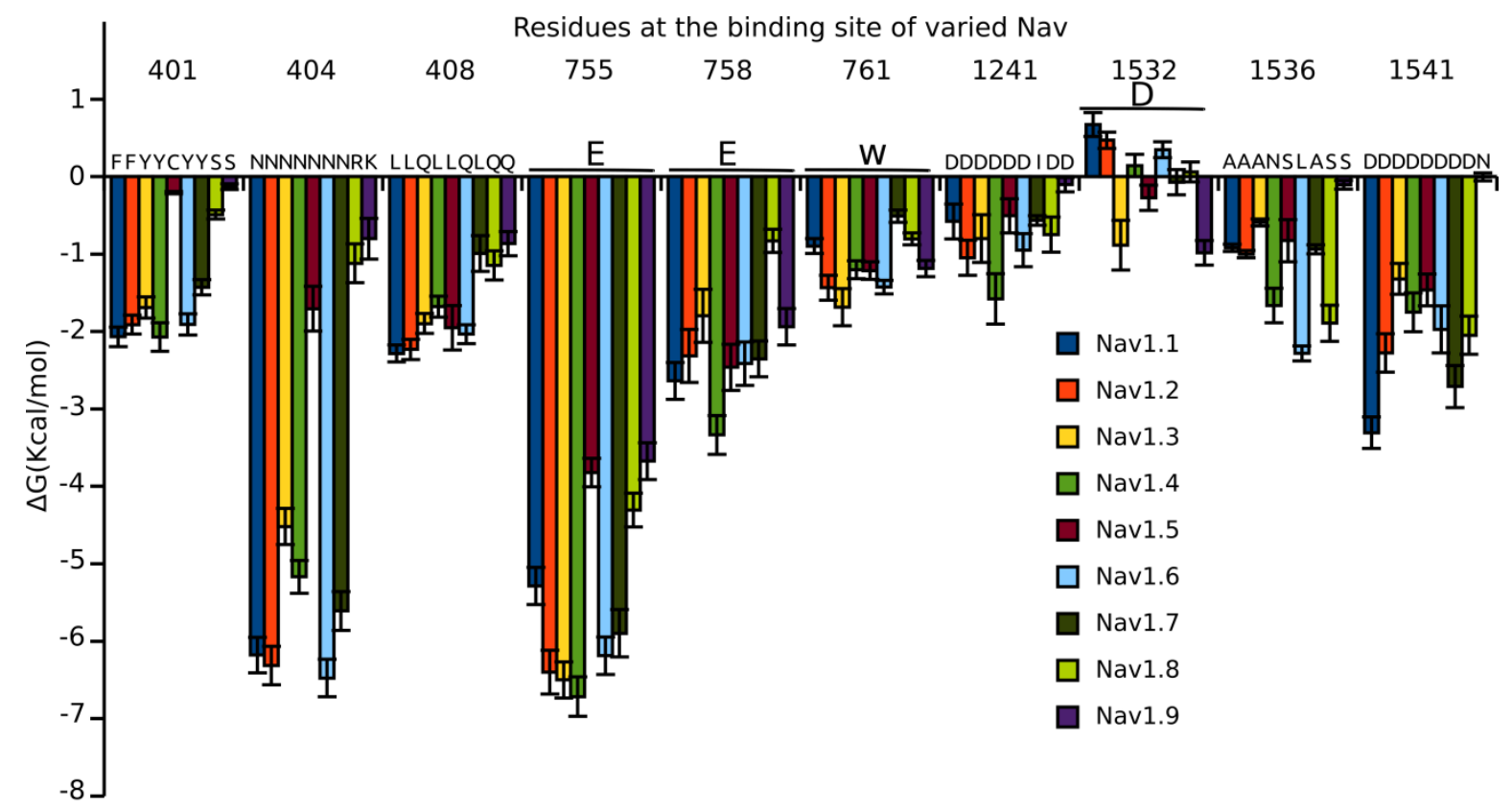

Figure 7. Energetic contribution of the residues at the binding site of varied $\mathrm{Na}_{\mathrm{V}}$ to the binding affinity of PIIIA. Residues at position 755, 758, 761, 1532 are conserved and are shown in bold. Residue side chain energetic contribution to the binding affinity of PIIIA to varied $\mathrm{Na}_{\mathrm{V}}$ subtypes from $\mathrm{Na}_{\mathrm{V}} 1.1$ to $\mathrm{Na}_{\mathrm{V}} 1.9$ are shown in different colors.

Overall, the binding site of $\mathrm{Na}_{\mathrm{V}}$ is rich of negatively charged residues such as $\mathrm{D}$ and $\mathrm{E}$, and thus the binding site shows an overall negative electrostatic potential (Figure S4). By contrast, the PIIIA contains six positively charged residues and shows the positive electrostatic potential that is complementary to that of the $\mathrm{Na}_{V}$ (Figure S4). Thus, the long range electrostatic interaction can be the driving force for the binding of PIIIA to the $\mathrm{NaV}$ at long range distance. At short range distance, the pairwise electrostatic interactions and hydrogen bond interactions contribute most to the binding affinity of PIIIA to $\mathrm{Na}_{\mathrm{V}}$ subtypes. Binding energy decomposition clearly shows that the conserved residues and the non-conserved residues have synergistic effects to affect the binding affinity of PIIIA to $\mathrm{Na}_{\mathrm{V}}$ subtypes. 


\section{Conclusions}

A computational method combining homology modeling, docking, molecular dynamics simulations and binding energy calculations was established and successfully applied to determine the specificity of PIIIA to varied $\mathrm{Na}_{V}$ subtypes from $\mathrm{Na}_{V} 1.1$ to $\mathrm{Na}_{V} 1.9$. The predicted binding free energies using umbrella sampling and MMGB/SA were correlated with experimental values giving a correlation coefficient $\left(\mathrm{R}^{2}\right)$ of 0.68 and 0.41 , respectively. The performance of umbrella sampling is superior to MMGB/SA due to the more powerful conformation sampling of the former. Interestingly, the predicted binding affinities given by umbrella sampling is very similar to the experimental values.

Binding modes analysis identified nonconserved residues existing at the interface between PIIIA and $\mathrm{Na}_{\mathrm{V}} 1 . \mathrm{x}(\mathrm{x}=1$ to 9). These nonconserved residues formed nonconserved interactions at the interface between PIIIA and $\mathrm{Na}_{\mathrm{V}}$ subtypes, which might confer the specificity of PIIIA. Indeed, results from binding energy decomposition showed that these nonconserved residues contributed varied binding energies to the binding affinity of PIIIA to varied $\mathrm{Na}_{\mathrm{V}}$ subtypes. Intriguingly, we also found that even the conserved residues could contribute varied binding energies to the binding of PIIIA to varied $\mathrm{Na}_{V}$ subtypes. Therefore, the conserved and nonconserved residues might play synergistic effects together to influence the specificity of PIIIA to varied $\mathrm{Na}_{\mathrm{V}}$ subtypes. Overall, results from this study are valuable for our understanding the molecular determinants that confer the specificity of PIIIA to varied $\mathrm{Na}_{V}$ subtypes and for further engineering the specificity of the $\mu$-conotoxins to the interested $\mathrm{Na}_{\mathrm{V}}$ subtypes.

Supplementary Materials: The following are available online at http://www.mdpi.com/1660-3397/16/5/153/s1.

Author Contributions: R.Y. and T.J. conceived and designed the experiments; F.C. performed the simulations; W.H. assisted with the umbrella sampling simulations; F.C. and R.Y. analyzed the data and wrote the paper.

Acknowledgments: This work was supported by the Fundamental Research Funds for the Central Universities (No. 201762011 for R.Y.), and the grant from National Natural Science Foundation of China (NSFC) (No. 81502977 for R.Y.), the Scientific and Technological Innovation Project Financially Supported by Qingdao National Laboratory for Marine Science and Technology (No. 2015ASKJ02) and the Taishan Scholars Program of Shandong, China.

Conflicts of Interest: The authors declare no conflict of interest. The founding sponsors had no role in the design of the study; in the collection, analyses, or interpretation of data; in the writing of the manuscript, and in the decision to publish the results.

\section{References}

1. Hodgkin, A.L.; Huxley, A.F. A quantitative description of membrane current and its application to conduction and excitation in nerve. J. Physiol. 1952, 117, 500-544. [CrossRef] [PubMed]

2. Noda, M.; Ikeda, T.; Suzuki, H.; Takeshima, H.; Takahashi, T.; Kuno, M.; Numa, S. Expression of functional sodium channels from cloned cDNA. Nature 1986, 322, 826-828. [CrossRef] [PubMed]

3. Rudy, B. Slow inactivation of the sodium conductance in squid giant axons. Pronase resistance. J. Physiol. 1978, 283, 1-21. [CrossRef] [PubMed]

4. Drenth, J.P.; Waxman, S.G. Mutations in sodium-channel gene SCN9A cause a spectrum of human genetic pain disorders. J. Clin. Investig. 2007, 117, 3603-3609. [CrossRef] [PubMed]

5. Catterall, W.A.; Goldin, A.L.; Waxman, S.G. International Union of Pharmacology. XLVII. Nomenclature and structure-function relationships of voltage-gated sodium channels. Pharmacol. Rev. 2005, 57, 397-409. [CrossRef] [PubMed]

6. Goldin, A.L. Diversity of mammalian voltage-gated sodium channels. Ann. N. Y. Acad. Sci. 1999, 868, 38-50. [CrossRef] [PubMed]

7. Shen, H.; Zhou, Q.; Pan, X.; Li, Z.; Wu, J.; Yan, N. Structure of a eukaryotic voltage-gated sodium channel at near-atomic resolution. Science 2017, 355. [CrossRef] [PubMed]

8. Yan, Z.; Zhou, Q.; Wang, L.; Wu, J.; Zhao, Y.; Huang, G.; Peng, W.; Shen, H.; Lei, J.; Yan, N. Structure of the $\mathrm{Na}_{V}$ 1.4-beta1 Complex from Electric Eel. Cell 2017, 170, 470.e11-482.e11. [CrossRef] [PubMed]

9. Terlau, H.; Olivera, B.M. Conus venoms: A rich source of novel ion channel-targeted peptides. Physiol. Rev. 2004, 84, 41-68. [CrossRef] [PubMed] 
10. Shon, K.J.; Olivera, B.M.; Watkins, M.; Jacobsen, R.B.; Gray, W.R.; Floresca, C.Z.; Cruz, L.J.; Hillyard, D.R.; Brink, A.; Terlau, H.; et al. mu-Conotoxin PIIIA, a new peptide for discriminating among tetrodotoxin-sensitive Na channel subtypes. J. Neurosci. 1998, 18, 4473-4481. [CrossRef] [PubMed]

11. Safo, P.; Rosenbaum, T.; Shcherbatko, A.; Choi, D.Y.; Han, E.; Toledo-Aral, J.J.; Olivera, B.M.; Brehm, P.; Mandel, G. Distinction among neuronal subtypes of voltage-activated sodium channels by mu-conotoxin PIIIA. J. Neurosci. 2000, 20, 76-80. [CrossRef] [PubMed]

12. Wilson, M.J.; Yoshikami, D.; Azam, L.; Gajewiak, J.; Olivera, B.M.; Bulaj, G.; Zhang, M.M. mu-Conotoxins that differentially block sodium channels $\mathrm{Na}_{\mathrm{V}} 1.1$ through 1.8 identify those responsible for action potentials in sciatic nerve. Proc. Natl. Acad. Sci. USA 2011, 108, 10302-10307. [CrossRef] [PubMed]

13. Munasinghe, N.R.; Christie, M.J. Conotoxins That Could Provide Analgesia through Voltage Gated Sodium Channel Inhibition. Toxins 2015, 7, 5386-5407. [CrossRef] [PubMed]

14. Korkosh, V.S.; Zhorov, B.S.; Tikhonov, D.B. Folding similarity of the outer pore region in prokaryotic and eukaryotic sodium channels revealed by docking of conotoxins GIIIA, PIIIA, and KIIIA in a Na $\mathrm{Ab}$-based model of Nav1.4. J. Gen. Physiol. 2014, 144, 231-244. [CrossRef] [PubMed]

15. Zhorov, B.S.; Tikhonov, D.B. Computational Structural Pharmacology and Toxicology of Voltage-Gated Sodium Channels. Curr. Top. Membr. 2016, 78, 117-144. [PubMed]

16. Bagneris, C.; DeCaen, P.G.; Naylor, C.E.; Pryde, D.C.; Nobeli, I.; Clapham, D.E.; Wallace, B.A. Prokaryotic $\mathrm{Na}_{V} \mathrm{Ms}$ channel as a structural and functional model for eukaryotic sodium channel antagonism. Proc. Natl. Acad. Sci. USA 2014, 111, 8428-8433. [CrossRef] [PubMed]

17. Nielsen, K.J.; Watson, M.; Adams, D.J.; Hammarstrom, A.K.; Gage, P.W.; Hill, J.M.; Craik, D.J.; Thomas, L.; Adams, D.; Alewood, P.F.; et al. Solution structure of mu-conotoxin PIIIA, a preferential inhibitor of persistent tetrodotoxin-sensitive sodium channels. J. Biol. Chem. 2002, 277, 27247-27255. [CrossRef] [PubMed]

18. Sali, A.; Blundell, T.L. Comparative protein modelling by satisfaction of spatial restraints. J. Mol. Biol. 1993, 234, 779-815. [CrossRef] [PubMed]

19. Webb, B.; Sali, A. Comparative Protein Structure Modeling Using MODELLER. Curr. Protoc. Bioinform. 2016, 54, 5.6.1-5.6.37.

20. Yu, R.; Craik, D.J.; Kaas, Q. Blockade of neuronal alpha7-nAChR by alpha-conotoxin ImI explained by computational scanning and energy calculations. PLoS Comput. Biol. 2011, 7, e1002011. [CrossRef] [PubMed]

21. Magrane, M.; UniProt, C. UniProt Knowledgebase: A hub of integrated protein data. Database (Oxford) 2011, 2011, bar009. [CrossRef] [PubMed]

22. Shen, M.Y.; Sali, A. Statistical potential for assessment and prediction of protein structures. Protein Sci. 2006, 15, 2507-2524. [CrossRef] [PubMed]

23. Morris, G.M.; Huey, R.; Lindstrom, W.; Sanner, M.F.; Belew, R.K.; Goodsell, D.S.; Olson, A.J. AutoDock4 and AutoDockTools4: Automated docking with selective receptor flexibility. J. Comput. Chem. 2009, 30, 2785-2791. [CrossRef] [PubMed]

24. Case, D.A.; Cerutti, D.S.; Cheatham, T.; Darden, T.; Duke, R.; Giese, T.J.; Gohlke, H.; Götz, A.; Greene, D.; Homeyer, N.; et al. AMBER 2017; University of California: San Francisco, CA, USA, 2017.

25. Maier, J.A.; Martinez, C.; Kasavajhala, K.; Wickstrom, L.; Hauser, K.E.; Simmerling, C. ff14SB: Improving the Accuracy of Protein Side Chain and Backbone Parameters from ff99SB. J. Chem. Theory Comput. 2015, 11, 3696-3713. [CrossRef] [PubMed]

26. Dupradeau, F.Y.; Pigache, A.; Zaffran, T.; Savineau, C.; Lelong, R.; Grivel, N.; Lelong, D.; Rosanski, W.; Cieplak, P. The R.E.D. tools: Advances in RESP and ESP charge derivation and force field library building. Phys. Chem. Chem. Phys. 2010, 12, 7821-7839. [CrossRef] [PubMed]

27. Frias Nunez, M. Plans for the establishment of central vaccination committees in the institutionalization of Medicine in Colombia. Cuad. Complut. Hist. Med. Cienc. 1993, 1, 89-102. [PubMed]

28. Lavery, R.; Zakrzewska, K.; Beveridge, D.; Bishop, T.C.; Case, D.A.; Cheatham, T., 3rd; Dixit, S.; Jayaram, B.; Lankas, F.; Laughton, C.; et al. A systematic molecular dynamics study of nearest-neighbor effects on base pair and base pair step conformations and fluctuations in B-DNA. Nucleic Acids Res. 2010, 38, 299-313. [CrossRef] [PubMed]

29. Grossfield, A.; Pitman, M.C.; Feller, S.E.; Soubias, O.; Gawrisch, K. Internal hydration increases during activation of the G-protein-coupled receptor rhodopsin. J. Mol. Biol. 2008, 381, 478-486. [CrossRef] [PubMed]

30. Huggins, D.J. Correlations in liquid water for the TIP3P-Ewald, TIP4P-2005, TIP5P-Ewald, and SWM4-NDP models. J. Chem. Phys. 2012, 136, 064518. [CrossRef] [PubMed] 
31. Dickson, C.J.; Madej, B.D.; Skjevik, A.A.; Betz, R.M.; Teigen, K.; Gould, I.R.; Walker, R.C. Lipid14: The Amber Lipid Force Field. J. Chem. Theory Comput. 2014, 10, 865-879. [CrossRef] [PubMed]

32. Miyamoto, S.; Kollman, P.A. Settle-An Analytical Version of the Shake and Rattle Algorithm for Rigid Water Models. J. Comput. Chem. 1992, 13, 952-962. [CrossRef]

33. Darden, T.; York, D.; Pedersen, L. Particle Mesh Ewald-An N.Log(N) Method for Ewald Sums in Large Systems. J. Chem. Phys. 1993, 98, 10089-10092. [CrossRef]

34. Wittayanarakul, K.; Hannongbua, S.; Feig, M. Accurate prediction of protonation state as a prerequisite for reliable MM-PB(GB)SA binding free energy calculations of HIV-1 protease inhibitors. J. Comput. Chem. 2008, 29, 673-685. [CrossRef] [PubMed]

35. Northrup, S.H.; Pear, M.R.; Lee, C.Y.; McCammon, J.A.; Karplus, M. Dynamical theory of activated processes in globular proteins. Proc. Natl. Acad. Sci. USA 1982, 79, 4035-4039. [CrossRef] [PubMed]

36. Kumar, S.; Bouzida, D.; Swendsen, R.H.; Kollman, P.A.; Rosenberg, J.M. The Weighted Histogram Analysis Method for Free-Energy Calculations on Biomolecules. 1. The Method. J. Comput. Chem. 1992, 13, 1011-1021. [CrossRef]

37. McArthur, J.R.; Singh, G.; O’Mara, M.L.; McMaster, D.; Ostroumov, V.; Tieleman, D.P.; French, R.J. Orientation of mu-conotoxin PIIIA in a sodium channel vestibule, based on voltage dependence of its binding. Mol. Pharmacol. 2011, 80, 219-227. [CrossRef] [PubMed]

38. Tietze, A.A.; Tietze, D.; Ohlenschlager, O.; Leipold, E.; Ullrich, F.; Kuhl, T.; Mischo, A.; Buntkowsky, G.; Gorlach, M.; Heinemann, S.H.; et al. Structurally Diverse mu-Conotoxin PIIIA Isomers Block Sodium Channel Nav1.4. Angew. Chem. Int. Ed. 2012, 51, 4058-4061. [CrossRef] [PubMed]

39. Wilson, M.J.; Zhang, M.M.; Gajewiak, J.; Azam, L.; Rivier, J.E.; Olivera, B.M.; Yoshikami, D. alpha- And beta-subunit composition of voltage-gated sodium channels investigated with mu-conotoxins and the recently discovered mu O-conotoxin GVIIJ. J. Neurophysiol. 2015, 113, 2289-2301. [CrossRef] [PubMed]

40. Zhang, M.M.; Wilson, M.J.; Azam, L.; Gajewiak, J.; Rivier, J.E.; Bulaj, G.; Olivera, B.M.; Yoshikami, D. Co-expression of $\mathrm{Na}(\mathrm{V})$ beta subunits alters the kinetics of inhibition of voltage-gated sodium channels by pore-blocking mu-conotoxins. Br. J. Pharmacol. 2013, 168, 1597-1610. [CrossRef] [PubMed]

41. Chen, R.; Chung, S.H. Complex Structures between the N-Type Calcium Channel $(\mathrm{Ca}(\mathrm{V}) 2.2)$ and omega-Conotoxin GVIA Predicted via Molecular Dynamics. Biochemistry 2013, 52, 3765-3772. [CrossRef] [PubMed]

42. Mahdavi, S.; Kuyucak, S. Why the Drosophila Shaker $\mathrm{K}^{+}$channel is not a good model for ligand binding to voltage-gated Kv1 channels. Biochemistry 2013, 52, 1631-1640. [CrossRef] [PubMed]

43. Patel, D.; Mahdavi, S.; Kuyucak, S. Computational Study of Binding of mu-Conotoxin GIIIA to Bacterial Sodium Channels $\mathrm{Na}(\mathrm{V}) \mathrm{Ab}$ and $\mathrm{Na}_{\mathrm{V}} \mathrm{Rh}$. Biochemistry 2016, 55, 1929-1938. [CrossRef] [PubMed]

44. Rashid, M.H.; Mahdavi, S.; Kuyucak, S. Computational Studies of Marine Toxins Targeting Ion Channels. Mar. Drugs 2013, 11, 848-869. [CrossRef] [PubMed]

45. Suresh, A.; Hung, A. Molecular simulation study of the unbinding of alpha-conotoxin [Upsilon4E]GID at the alpha7 and alpha4beta2 neuronal nicotinic acetylcholine receptors. J. Mol. Graph. Model. 2016, 70, 109-121. [CrossRef] [PubMed]

46. Yu, R.L.; Tabassum, N.; Jiang, T. Investigation of alpha-conotoxin unbinding using umbrella sampling. Bioorg. Med. Chem. Lett. 2016, 26, 1296-1300. [CrossRef] [PubMed]

(C) 2018 by the authors. Licensee MDPI, Basel, Switzerland. This article is an open access article distributed under the terms and conditions of the Creative Commons Attribution (CC BY) license (http://creativecommons.org/licenses/by/4.0/). 